\title{
FORMAÇÃO PROFISSIONAL DE CUIDADOR DE IDOSOS ATUANTES EM INSTITUIÇÕES DE LONGA PERMANÊNCIA
}

\author{
I. L. S. SILVA' ${ }^{1}$ F. C. A. MACHADO ${ }^{1 *}$, M. Â. F. FERREIRA ${ }^{2}$ e M. P. RODRIGUES ${ }^{2}$ \\ ${ }^{1}$ Instituto Federal de Educação, Ciência e Tecnologia do Rio Grande do Norte \\ Universidade Federal do Rio Grande do Norte \\ flavitamachado@yahoo.com.br \\ Artigo submetido em julho/2015 e aceito em dezembro/2015 \\ DOI: $10.15628 /$ holos.2015.3215
}

\begin{abstract}
RESUMO
Trata-se de um estudo descritivo e analítico com abordagem quantitativa cujo objetivo foi investigar a formação profissional dos cuidadores atuantes em Instituições de Longa Permanência para Idosos (ILPIs) em Natal/RN no ano de 2014. Para tanto, aplicou-se um questionário semiestruturado a 63 cuidadores de nove ILPIs, representando $75 \%$ do total de profissionais exercendo atividades nessas instituições. O questionário viabilizou a captação de dados relativos ao perfil socioeconômico e à formação profissional do cuidador. Os dados foram analisados mediante observação das frequências absolutas e relativas e medidas de tendência central das variáveis numéricas. Assim, identificou-se que a maioria dos cuidadores possuía baixa condição
\end{abstract}

socioeconômica e não apresentava curso específico para exercer a função de cuidador. Contudo, entre aqueles que realizaram cursos, grande parte relata que os conteúdos abordados durante a formação deram segurança para a práxis do cuidado, embora refiram à necessidade de se capacitar. No geral, os resultados apontam que há, possivelmente, uma inadequada capacitação formal para o exercício da ocupação, em meio ao relato de cursos de 01 semana $(n=20$ entrevistados) cujas atividades práticas consistem em aulas demonstrativas. Isto revela fragilidades na formação que estariam relacionadas à ausência de um currículo básico para orientar a formação e a baixa escolaridade requisitada ao exercício dos profissionais.

PALAVRAS-CHAVE: Envelhecimento, profissional da saúde, cuidador, idoso, Instituição de Longa Permanência par a Idosos.

\section{VOCATIONAL TRAINING OF CAREGIVER WHO WORKS INHOMES FOR THE AGED}

\begin{abstract}
This is a cross-sectional, descriptive and analytical study with a quantitative approach which aimed to investigate the vocational training of caregivers who works in Homes for the Aged (HFA) in Natal / RN in the year of 2014. Therefore, semi-structured questionary was applied to 63 caregivers in 09 HFA, representing $75 \%$ of caregivers who works in these institutions. The questionary captured data related to the socioeconomic profile and to the vocational training about caring profession. These data were analyzed by observing absolute e relative frequencies and measures of central tendency of the numeric variables. In general, it was found that most of caregivers was from low socioeconomic status and
\end{abstract}

started to practice the occupation without conducting a previous specific course. However, among those who attended a course, most report that the contents saw in the curriculum provided security for the praxis of care, but these people also reported the need for training. In general, the results, probably, show that there is an inadequate formal training to practice the caregiver's occupation, amid reports of short 01 week courses ( $n=20$ interviewed) which practical activities consist of demonstration lessons. This reveals weaknesses in professional qualification that would related to the absence of a guiding core curriculum and the low education required for professional practice.

KEYWORDS: Aging, Health Personnel, Caregivers, Aged, Homes for the Aged. 


\section{INTRODUÇÃO}

O Brasil vivencia o processo global de envelhecimento populacional e suas consequências como o aumento das doenças crônico-degenerativas. Não obstante, há a persistência de doenças infectocontagiosas e surgimento dos agravos à saúde, panorama conhecido por tripla carga de doenças (MENDES, 2010). Assim, processa-se uma transição demográfica e epidemiológica que implica transformações sociais na esfera governamental, dos serviços de saúde e da família. Na primeira destas esferas, por exemplo, existe a necessidade de reorganização do sistema previdenciário e de saúde; na segunda há a necessidade de modificar práticas assistenciais e na terceira é necessário reorganizar as funções sociais dos familiares. No caso, a família precisa estar apta a cuidar dos parentes idosos. Todavia, cada vez mais é frequente a ausência de um membro para tal função, seja pelo fato da família não apresentar um indivíduo mais jovem ou pelo despreparo em si para o cuidar do outro.

Diante da possibilidade de o cuidador ser um profissional ou um familiar, pode-se destacar a discussão do cuidador de idosos nos contextos dos serviços e da família. O cuidador é a pessoa que oferece cuidados para suprir a incapacidade funcional, temporária ou definitiva e pode ser classificado como "formal" (profissional contratado) ou "informal" (familiares, amigos ou voluntários) (CALDAS, 2002). O cuidador formal seria aquele que recebe treinamento específico para a função e mantém vínculos profissionais para exercer a atividade de cuidar, mediante uma remuneração (BORN, 2006, p.3). Esse profissional pode ser contratado para trabalhar na moradia do idoso (cuidador domiciliário) ou numa Instituição de Longa Permanência para Idosos - ILPI (cuidador institucional). As ILPIs são Instituições governamentais ou não governamentais, de caráter residencial, destinadas a domicílios coletivos de pessoas com idade igual ou superior a 60 anos, com ou sem suporte familiar, em condições de liberdade, dignidade e cidadania (ANVISA, 2005, p. 2).

Especificamente, destaca-se a discussão sobre o cuidador institucional em decorrência dos seguintes fatos: o aumento das doenças crônicas nos idosos (oportunizadas pela maior longevidade da população), as mudanças na composição familiar e a dependência para realização das atividades de vida diária. Esses fatores aliados à ausência de um cuidador domiciliário geram a necessidade da institucionalização.

Portanto, as ILPIs, representadas na figura dos profissionais, têm o compromisso de auxiliar os idosos a suplantar as dificuldades diárias relacionadas ao envelhecimento seja no âmbito físico, psicológico, cognitivo ou social. Neste sentido, o cuidador é essencial para a melhoria da qualidade de vida do idoso realizando atividades como supervisões e auxílios na administração de medicamentos, alimentação, higienização e acompanhamentos em consultas médicas, entre outras atividades (BRASIL, 2012). Desta forma, é necessária uma formação profissional adequada, implicando a estruturação de cursos de formação que abarquem conteúdos curriculares pertinentes às habilidades e competências esperadas de um cuidador. Todavia, a profissão ainda aguarda aprovação e regulamentação pelo Congresso Nacional Brasileiro o que propicia uma diversidade de estruturas curriculares disseminadas. Assim, faz-se necessário discutir qual seria o currículo mais adequado diante das demandas.

Diante do exposto, este estudo procurou investigar a formação profissional dos cuidadores 
formais que trabalham na assistência aos idosos institucionalizados na cidade de Natal/RN, no ano de 2014. Para tanto, foi necessário verificar os aspectos relativos ao nível de formação profissional e os conteúdos estudados pelos cuidadores. Nessa perspectiva, esse trabalho busca contribuir para o aprimoramento do processo de formação profissional do cuidador e, especificamente, avaliar quem são os cuidadores em atividade no município de Natal/RN. De fato, esta é uma discussão necessária posto que integra a perspectiva de agregar vida aos anos de vida, contribuindo para que a velhice seja uma fase acompanhada de satisfação para o idoso e para aqueles que o cercam (INOUYE; PEDRAZZANI; PAVARINI, 2010).

\section{REVISÃO BIBLIOGRÁFICA}

Os componentes demográficos de fecundidade, mortalidade e migração são determinantes no processo de envelhecimento de uma população. A fecundidade em especial, pois, mesmo que a quantidade de idosos se eleve em decorrência do declínio dos níveis de mortalidade, esse efeito será amenizado caso as taxas de fecundidade se mantenham altas (ALONSO, 2010). Ressalta-se que, entre as décadas de 1940 e 1960, o Brasil, assim como a maioria dos países da América Latina, experimentava um declínio significativo da mortalidade, associado a uma fecundidade constante (WONG; CARVALHO; 2006).

Essa transição da fecundidade brasileira, iniciada no final da década de 1960, foi resultante de uma série de transformações econômicas, sociais, culturais e institucionais na sociedade, e, de acordo com Perpétuo e Wong (2003), o Estado teve, direta ou indiretamente, um papel determinante nesse processo. Isso ocorreu através da implantação de ações governamentais de desenvolvimento e modernização, de políticas e programas de controle da natalidade e de projetos de planejamento familiar. Nessa perspectiva, considera-se que as rápidas transformações no perfil demográfico do Brasil em direção a uma população bastante envelhecida devem ser acompanhadas por medidas que promovam o bem-estar da sociedade.

No processo de envelhecimento, aumentam as possibilidades de se contrair uma doença crônica. No Brasil, verificou-se que 77,4\% das pessoas com 60 anos ou mais de idade declararam ter doenças. Esta proporção aumenta para $80,3 \%$ no contingente de idosos com 75 anos ou mais de idade (IBGE, 2010). As condições crônicas apresentam um grande potencial para desencadear dependência e incapacidade nessa faixa etária. Por isso, a incapacidade funcional é um conceito importante para avaliar as condições de saúde de idosos. A perda da capacidade funcional é referenciada como a perda das habilidades físicas e mentais necessárias para a realização de suas atividades básicas e instrumentais da vida diária (BRASIL, 2006).

Gaioli, Furegato e Santos (2012) analisam que, com o avançar da doença, as demandas por cuidados se tornam mais complexas e constantes, havendo a indicação de cuidador formal com capacitação profissional. Apesar disso, a presença de um profissional capacitado para esta atividade não é uma realidade frequente. A situação é desafiadora para a área da saúde, pois, à medida que envelhece, mais dependente o idoso se torna na execução de suas atividades da vida diária. A evolução da doença ocorre e, certamente, o cuidador, em algum momento, ampliará suas tarefas para o cuidado. 
Lima (2011) relata que, conforme a legislação brasileira - Constituição Federal de 1988 (BRASIL, 1988), a Política Nacional do Idoso (BRASIL, 1994) e o Estatuto do Idoso (BRASIL, 2003) -, o principal responsável pelo cuidado com o idoso é a família. A assistência prestada pela família está concentrada na figura do cuidador principal. Ela predomina como suporte informal, sendo as mulheres as principais cuidadoras (CALDAS, 2002). Embora o cuidado familiar esteja culturalmente arraigado à sociedade, esta não é a realidade de todos os idosos. Há idosos cujas famílias não podem oferecer suporte financeiro para garantir o cuidado adequado ou que não conseguem conciliar a função de cuidadores com a vida cotidiana. Ademais, a redução da taxa de fecundidade, as mudanças nos padrões de nupcialidade e a crescente inserção da mulher no mercado de trabalho, reduzem a disponibilidade de cuidadores familiares. Assim, as ILPIs surgem como uma opção para idosos cujas famílias não dispõem de um cuidador e para aqueles que são vítimas de abandono e/ou com sequelas de doenças crônicas (CAMARANO; KANSO, 2010; CALDAS, 2002).

As instituições de longa permanência para idosos assumem a responsabilidade de cuidar quando o idoso perde seus vínculos com sua rede social, dando suporte ou assistindo suas necessidades com a finalidade de melhorar sua saúde e a qualidade de vida (BESSA et al., 2012, p. 178). As ILPIs são divididas em três modalidades, quando se considera o grau de dependência do idoso, tais como: Modalidade I, Modalidade II e Modalidade III. A Modalidade I é direcionada aos idosos autônomos em suas atividades da vida diária, mesmo que necessitem de algum equipamento de autoajuda; a Modalidade II é destinada aos idosos dependentes e independentes que precisam de ajuda e cuidados específicos, com acompanhamento e controle adequado de profissionais da área da saúde e a Modalidade III, que é dirigida aos idosos dependentes que precisam de assistência total em, pelo menos, uma atividade da vida diária (DIOGO; DUARTE, 2002). Não obstante, existe ainda a classificação das ILPIs de acordo com a quantidade de idosos, conforme Decreto № 8.553/2008 (NATAL, 2008) em: a) Porte I: de 01 a 20 idosos; b) Porte II: de 21 a 40 idosos; c) Porte III: de 41 a 60 idosos e d) Porte IV acima de 60 idosos.

$\mathrm{O}$ atendimento aos idosos no Brasil exige que a ILPI preste serviços tanto na área social quanto na área sanitária, sendo, pois, objeto de ação de ambas as esferas. Pode-se dizer, portanto, que a ILPI é um tipo especial de instituição de natureza sociossanitária. Essa natureza híbrida demanda a criação de um modelo sociossanitário de assistência, que conjugue valores e práticas de ambas as esferas (SIMSON; PINTO, 2012).

Em 2005, passou a vigorar a Resolução da Diretoria Colegiada (RDC) no 283. Esta Resolução estabelece normas de funcionamento dessas instituições e define quais são os graus de dependência e as condições gerais de organização institucional baseadas nos direitos dos idosos, incluindo recursos humanos, infraestrutura, processos operacionais, notificação compulsória, monitoramento e avaliação (ANVISA, 2005). No artigo referente a recursos humanos para cuidados aos idosos, especifica-se o número de cuidadores que uma ILPI deverá possuir em função do grau de dependência e do número de idosos, mas não esclarece a qualificação exigida.

Para oferecer um atendimento de qualidade, também é fundamental que essas instituições assegurem aos profissionais o espaço para supervisão, estudos e reuniões. Além da qualificação continuada, esse contato entre profissionais é importante para que eles possam dividir suas dúvidas, angústias e anseios (SILVA, 2005). Segundo Camarano e Pasinato (2004), ainda que a legislação brasileira relativa aos cuidados com o idoso seja considerada por especialistas como 
bastante avançada, na prática ela se mostra insatisfatória. O papel falho do Estado não está apenas na insuficiência da quantidade de vagas que disponibiliza, mas, essencialmente, no descaso com estas instituições, e na falta de supervisão adequada, transformando-as, assim, em ambientes refletores do abandono. Diante disso, é pertinente pensar a importância do cuidador de idosos.

O cuidador é a pessoa que oferece cuidados para suprir a incapacidade funcional, temporária ou definitiva. A figura do cuidador já é assimilada, nos países desenvolvidos, como um parceiro da equipe de saúde, mas isso não acontece no Brasil, efetivamente (BRASIL, 1999a).

Os cuidadores podem ser classificados de acordo com os vínculos mantidos com a pessoa a quem endereçam os cuidados em cuidadores formais e informais. Caldas (2002) utilizou a denominação cuidador formal (principal ou secundário) para o profissional contratado, e a expressão cuidador informal para os familiares, amigos e voluntários.

Assim, os cuidadores formais são profissionais capacitados para o cuidado, contribuindo de forma significativa para a saúde das pessoas cuidadas (ROCHA et al., 2008). Adicionalmente, o cuidador formal é descrito como sendo "a pessoa capacitada para auxiliar o idoso que apresenta limitações para realizar as atividades da vida cotidiana, fazendo elo entre o idoso, a família e os serviços de saúde ou da comunidade, geralmente remunerado" (BORN, 2006, p. 7). Esse profissional pode ser contratado para trabalhar na moradia do idoso e, nesse caso, costuma ser chamado de cuidador domiciliário. Quando trabalha numa ILPI, passa a ser identificado como cuidador institucional.

O cuidador formal deve apresentar habilidades e qualidades para exercer sua prática. Segundo Born (2006) essas compreendem:

- Habilidades técnicas: São o conjunto de conhecimentos teóricos e práticos, adquiridos por meio da orientação de profissionais especializados. Esses conhecimentos prepararão o cuidador para prestar atenção e cuidados ao idoso.

- Qualidades éticas e morais: São atributos necessários para permitir relações de confiança, dignidade e respeito, que permitam assumir responsabilidades com iniciativa.

- Qualidades emocionais: O cuidador deve possuir domínio e equilíbrio emocional, facilidade de relacionamento humano, capacidade de compreender os momentos difíceis vividos pelo idoso e também ter tolerância diante das situações de frustração pessoal.

- Qualidades físicas e intelectuais: Ele deve possuir saúde física, incluindo-se força e energia, condição essencial nas situações em que haja necessidade de carregar o idoso ou lhe dar apoio para se vestir e cuidar da higiene pessoal. Deve ser capaz de avaliar e administrar situações que envolvem ações e tomada de decisões.

A profissão de cuidador de idosos é reconhecida e inserida na Classificação Brasileira de Ocupações (CBO) do Ministério do Trabalho e Emprego com o Código 5162-10. Segundo a CBO, a ocupação de cuidador é descrita como o indivíduo que cuida de idosos, a partir de objetivos estabelecidos por instituições especializadas ou responsáveis diretos, zelando pelo bem-estar, 
saúde, alimentação, higiene pessoal, educação, cultura, recreação e lazer da pessoa assistida (BRASIL, 2002, p. 4).

Quanto às condições gerais de exercício do trabalho dos cuidadores, a CBO determina que o trabalho possa ser exercido em domicílios ou instituições cuidadoras de crianças, jovens, adultos e idosos, com alguma forma de supervisão, na condição de trabalho autônomo ou assalariado (BRASIL, 2002). A carga horária é variável, podendo ser integral, com revezamento de turno ou por períodos determinados (BRASIL, 1999b).

Ainda, em relação a profissão de cuidador, o Projeto de Lei (PL) №. 4702 de 09 de novembro de 2012, que trata da regulamentação da profissão, coloca em seu art. 3o que poderá exercer a profissão de cuidador, o maior de 18 (dezoito) anos, com ensino fundamental completo e que tenha concluído, com aproveitamento, curso de formação de cuidador de pessoa idosa, de natureza presencial ou semipresencial, conferido por instituição de ensino reconhecida por órgão público federal, estadual ou municipal competente (BRASIL, 2012, p. 2). Ressalte-se que aqueles já atuantes há pelo menos dois anos, mas sem a qualificação exigida terão cinco anos para se adequar às exigências da lei.

Há quatro pontos fundamentais nas atividades de um cuidador: a) apoio emocional na convivência social do idoso; b) auxílio nas rotinas de higiene pessoal, de ambiente e de alimentação; c) cuidados preventivos; d) administração de medicamentos; e) outros procedimentos de saúde e f) amparo na mobilidade (BRASIL, 2012). Contudo, o fato de que saber medicar e dar banho e alimentação nas horas certas não faz da pessoa um profissional ideal para cuidar de idosos. A falta de capacitação, de conhecimento e de prática do profissional que presta cuidados ao idoso gera insegurança, desorganização, irritação e falta de humanismo nele próprio. Portanto, é imprescindível saber identificar e treinar as habilidades e qualidades necessárias à ocupação, quando da formação dos cuidadores (FREITAS; NORONHA, 2010). Ainda, em uma perspectiva mais ampla do cuidado, o papel do cuidador ultrapassa o simples acompanhamento de atividades diárias; porém não fazem parte da sua rotina, técnicas e procedimentos identificados como profissões legalmente estabelecidas, particularmente, na área da enfermagem (BRASIL, 2012).

Até o momento, o processo para qualificar cuidadores é considerado difícil por depender de uma complexidade de fatores, dentre os quais: leis que deem suporte a esse trabalhador e o investimento das ILPIs nesse processo, já que estas instituições vêm empregando cuidadores com ou sem qualificação. $O$ processo de qualificação pretende subsidiar uma formação humana e integral na qual o objetivo profissionalizante não tenha uma finalidade em si, nem seja orientado pelos interesses somente do mercado de trabalho, mas se constitua em uma possibilidade para a construção dos projetos de vida dos estudantes (FRIGOTTO; CIAVATTA; RAMOS, 2005). Além desta dificuldade quanto a qualificação da formação, o trabalho de cuidador em si é reconhecido como um trabalho frequentemente instável, mal remunerado, com possibilidade quase inexistente de formação, de promoção e de carreira e com direitos sociais limitados. Até hoje não existem as diretrizes curriculares nacionais relacionadas à profissão de cuidador, dificultando a convergência para um currículo unificado. 
Enfim, em meio às questões aqui colocadas, percebe-se a necessidade de estudar o processo de formação do cuidador de idoso. De fato, há uma tendência à inserção cada vez mais significativa deste profissional na sociedade, que mundialmente, vivencia o processo de envelhecimento.

\section{MÉTODO}

Este estudo caracteriza-se como uma pesquisa descritiva, exploratória, de caráter analítico utilizando abordagem quantitativa. O cenário do estudo foram nove ILPIs (seis filantrópicas e três privadas) das 14 existentes em Natal no ano de 2014. No caso, o município de Natal apresenta quatro zonas administrativas nas quais essas ILPIs estão distribuídas; uma na zona norte, nove na zona sul, duas na zona leste e duas na zona oeste. Do total das ILPIs, oito ILPIs são privadas com fins lucrativos e seis são privadas sem fins lucrativos - ou filantrópicas; não havendo ILPI pública (COVISA, 2014). Ressalte-se que as 14 ILPIs foram contatadas para participarem da pesquisa via contato telefônico e presencial; contudo 04 ILPIs privadas localizadas na zona sul não aceitaram a realização das entrevistas e 01 ILPI privada também localizada na zona sul foi excluída por não haver em seu quadro funcional cuidadores de idosos, sendo a função exercida por Técnicos de Enfermagem. Assim, participaram do estudo 100\% das ILPIs filantrópicas e 37,5\% das privadas. Essas ILPIs abrigavam em média 36 idosos \pm 23,51 (mínimo 13; máximo 83).

Os sujeitos deste estudo foram os cuidadores de idosos em exercício da assistência no momento da coleta de dados, excluindo-se aqueles em período de férias ou em gozo de licença de qualquer natureza. Mediante esses critérios, o estudo englobou $75 \%(n=63)$ do total de cuidadores $(n=84)$ das ILPIs avaliadas.

Os cuidadores participantes responderam a um questionário semiestruturado aplicado por um único pesquisador nos períodos de 01 a 30 de junho e 01 a 30 de outubro de 2014. Este realizava as perguntas, registrando as respostas por escrito e armazenando em arquivos de áudio (mp3) via gravador digital. A data e horário da coleta de dados foi agendada previamente com a administração das ILPIs. O intuito foi viabilizar uma coleta individual em ambiente reservado sem prejudicar o funcionamento habitual das ILPIs. Neste sentido, caso houvesse necessidade, a entrevistada poderia ser interrompida ou até mesmo remarcada.

Os dados captados eram relativos ao "Perfil socioeconômico" (caracterização do cuidador quanto a idade, naturalidade, sexo, estado civil, composição familiar, escolaridade, renda pessoal e familiar) e "formação profissional" (realização de curso específico para cuidador de idosos, tempo de duração do curso, conteúdos curriculares estudados, existência de atividades práticas no currículo, tempo de ocupação na profissão, tempo de formação do cuidador, realização de curso de capacitação e/ou treinamento após a formação específica de cuidador formal). Frise-se que se realizou o pré-teste do questionário com um grupo de cinco cuidadores de uma das ILPIs para verificar a eventual necessidade de correções e reajustes. A coleta das informações do pré-teste demonstrou que as questões elaboradas estavam claras e compreensíveis.

O protocolo desta pesquisa foi submetido e aprovado pelo CEP HUOL da UFRN (Número do Parecer: 628.400 e CAAE- de número 30677314.6.0000.5292) conforme indicativo da Resolução 466/2012 do Conselho Nacional de Saúde. 
Por tratar-se de estudo descritivo, a análise dos dados consistiu na observação das frequências absolutas e relativas calculadas com auxílio do software de livre acesso PSPP.

\section{RESULTADOS E DISCUSSÃO}

\subsection{Perfil socioeconômico dos participantes}

A maioria dos cuidadores de idosos das ILPIs de Natal/RN é do sexo feminino ( $n=54 ; 85,7 \%$ ), casadas $(n=53 ; 52,3 \%)$, idade de 40 a 49 anos $(n=22 ; 34,9 \%)$, residentes nas Zonas Norte $(n=25$; $39,7 \%$ ) e Oeste $(n=24 ; 38,1 \%)$ da cidade, suas famílias são compostas entre 01 e 03 pessoas ( $n=31$; 49,2\%), remuneração mensal de até 01 salário mínimo ( $n=45 ; 7$ 1,4\%) e renda familiar de 01 a 02 salários ( $n=40 ; 63,5 \%)$. Quanto à escolaridade, 60,4\% ( $n=38)$ têm até o ensino médio incompleto.

Em relação à idade, deve-se salientar que esta é um aspecto importante a ser observado na atividade de cuidador, pois a dependência dos idosos, principalmente em relação às atividades da vida diária, demanda esforço físico daqueles que atuam na função (RIBEIRO et al., 2008). Portanto, cuidadores idosos não seriam indicados. De fato, cuidadores idosos estão mais presentes no âmbito familiar, onde idosos estão cuidando de idosos, conforme indicado por Karsch (2003). Neste sentido, as ILPIs estudadas estariam em conformidade a perspectiva de dispor de cuidadores com potencial força física para a práxis, já que a idade média encontrada foi de 38,9 anos (desviopadrão: 9,98; mínimo: 20 anos, máximo: 59 anos).

No tocante ao estado civil dos cuidadores, não houve preponderância expressiva de um estado civil sobre outro (casado: $n=33,52,3 \%$; solteiro: $n=28,44,4 \%$ ). Entretanto, em relação ao sexo, os dados coletados estão em sintonia com a tradição histórica e cultural em que o cuidador formal de idosos institucionalizados é predominantemente mulher. $\mathrm{O}$ ato de cuidar foi - e ainda é -atribuído a mulher. A literatura afirma que isto se deve ao papel culturalmente desempenhado de cuidar da família, da casa, dos filhos e parentes (SALIBA et al., 2007); corroborando para a caracterização da mulher como cuidadora nata. Portanto, em meio a esta predominância de mulheres, observa-se a necessidade de mais cuidadores do sexo masculino para facilitar as atividades diárias de cuidados dos idosos, principalmente aquelas que exigem maior esforço físico. Além disso, a presença de cuidadores homens pode facilitar uma maior empatia com idosos do sexo masculino, propiciando uma relação mais próxima entre cuidador/idoso.

Dentre as regiões administrativas onde residem os cuidadores, destacam-se as Zonas Norte e Oeste da cidade - onde tradicionalmente se concentra a população de baixa renda e com menor tempo de investimento em educação e qualificação profissional. Fato respaldado por França (2001) que, analisando as zonas administrativas da cidade de Natal/RN, revela que as zonas Oeste e Norte despontam como as mais deprimidas social e economicamente. E assim, a profissão de cuidador apresenta-se como uma alternativa para inserção no mercado de trabalho por exigir legalmente o Ensino Fundamental completo para o seu exercício (BRASIL, 2012). De fato, o nível de escolaridade dos cuidadores está congruente com esta colocação acerca da baixa escolaridade, posto que $27 \%$ $(n=17)$ cursaram apenas o Ensino Fundamental incompleto. Todavia, este nível de escolaridade ainda é inferior ao discriminado no artigo terceiro do $P L n=4702 / 2012$ e, portanto, inadequado. $O$ referido projeto de Lei evidencia em seu terceiro parágrafo que poderá exercer a profissão de 
cuidador de idoso, o indivíduo maior de 18 anos de idade, com ensino fundamental completo e que tenha concluído curso de formação de cuidador em instituição de ensino reconhecida por órgão público federal, estadual ou municipal competente. Isto em si, reforça a necessidade veemente de regulamentação desta normativa para que possa haver uma formação de cuidador de idosos coerente com as competências (cognitivas, habilidades, relacionais) necessárias a um cuidador profissional.

Por outro lado, 34,9\% $(n=22)$ dos entrevistados possuem Ensino Médio completo. Isto estaria, inicialmente, incongruente com o estudo sobre "uma análise sociodemográfica dos cuidadores formais de idosos institucionalizados no município de Natal/RN", realizado por Araújo (2013) quando afirma que o grau de instrução predominante dos cuidadores da nossa cidade é o Ensino Médio completo. Neste ponto, frise-se que esta preponderância encontrada por Araújo (2013) ocorreu nas ILPIs privadas, mas nas ILPIs filantrópicas, que caracterizam a maioria da amostra deste estudo, predominou a escolaridade inferior ao ensino médico completo $(50,8 \%)$.

Por fim, em relação à escolaridade, frise-se que o cuidador de idosos das ILPIs de Natal está, em sua maioria, adequado ao perfil discriminado pelo PL no 4702/2012, haja vista que 73\% dos trabalhadores possuem minimamente o Ensino Fundamental completo. No entanto, vale ressaltar que o grau de escolaridade não é exigido pelas Instituições para a contratação, o que contribui para uma assistência de baixa qualidade. De fato, ao analisar-se que os cuidadores devem seguir prescrições médicas e manusear medicamentos, o grau de escolaridade deve ser analisado com cautela (SALIBA et al.,2007).

A caracterização dos cuidadores como integrantes do grupo de baixa condição socioeconômica pode ser inferida pela escolaridade e pela renda desses profissionais, tanto pessoal (até 01 salário mínimo) quanto familiar (01 a 02 salários). Ressalte-se que 15,9\% ( $n=10)$ dos cuidadores são os únicos responsáveis pelo provento familiar. A baixa remuneração pode levar os cuidadores a buscar uma forma de complementação salarial, contribuindo para o estresse destes profissionais conforme pesquisa sobre o "perfil dos cuidadores de idosos nas instituições de longa permanência de Belo Horizonte/MG" realizada por Ribeiro et al. (2008).

\subsection{Formação profissional}

Em relação à formação profissional, a maioria dos cuidadores possui curso específico de cuidador de idosos. Entretanto, na contramão do que poderia ser inferido, acredita-se que esses cursos não subsidiariam, necessariamente, uma formação profissional adequada. Isto porque, somando-se o quantitativo de cuidadores que relataram ter feito curso específico ou que estariam cursando ( $n=43,68,3 \%)$, obteve-se um percentual de $46,5 \%(n=20)$ de cuidadores cujos cursos tiveram uma duração de até 01 semana. Ao serem indagados quanto à realização de atividades práticas no curso, dos 43 cuidadores, $74,4 \%(n=32)$ disseram que essas foram contempladas no curso (ver tabela 1).

O alto percentual de cuidadores com curso de até 01 semana de duração denota uma grande fragilidade na formação de cuidador, que é a ausência de uma matriz curricular específica e, atrelado a isso, de uma carga horária mínima para as disciplinas. Ademais, o relato de realização de atividades práticas no curso é algo questionável. Isto porque, ao se observar que 32 
entrevistados disseram ter realizado atividade prática e 20 afirmaram que seus cursos eram de até 01 semana, percebe-se uma incompatibilidade. Durante as entrevistas muitos cuidadores disseram que as práticas consistiam em demonstrações pelo professor de como proceder mediante situações como um engasgo. Assim, houve, quando muito, uma aula demonstrativa e não uma prática. Inclusive, foi relatada a dispensa das atividades práticas quando o estudante do curso específico de cuidador exercia formalmente a atividade de cuidador. Isto evidencia o quanto é preciso progredir na formação do cuidador, bem como na atenção dispensada aos idosos como um todo. Tal necessidade seria esperada, posto que o Brasil vivencia ainda uma transição demográfica e epidemiológica, sendo o "enfrentamento" do envelhecimento algo recente em nossa história.

Tabela 01: Formação profissional do cuidador de idosos das ILPIs, Natal, RN, Brasil, 2014.

\begin{tabular}{|c|c|c|c|}
\hline \multicolumn{4}{|c|}{ FORMAÇÃO PROFISSIONAL DO CUIDADOR DE IDOSOS DAS ILPIS } \\
\hline VARIÁVEL & CATEGORIA & $\mathrm{N}$ & $\%$ \\
\hline \multirow{3}{*}{$\begin{array}{l}\text { Possui curso de cuidador } \\
\qquad(n=63)\end{array}$} & Sim & 41 & 65,1 \\
\hline & Não & 20 & 31,7 \\
\hline & Em curso & 02 & 3,2 \\
\hline \multirow{6}{*}{$\begin{array}{l}\text { Duração do curso de cuidador } \\
\qquad(n=43)\end{array}$} & 01 semana & 20 & 46,5 \\
\hline & Até 01 mês & 06 & 14,0 \\
\hline & Até 02 meses & 06 & 14.0 \\
\hline & Até 03 meses & 08 & 18,6 \\
\hline & Até 04 meses & 01 & 2,3 \\
\hline & Mais de 04 meses & 02 & 4,7 \\
\hline \multirow{2}{*}{$\begin{array}{l}\text { Atividade prática durante o curso } \\
\qquad(n=43)\end{array}$} & Sim & 32 & 74,4 \\
\hline & Não & 11 & 26,2 \\
\hline
\end{tabular}

Fonte: Pesquisa de campo. Natal, RN, Brasil, 2014.

Quanto aos conteúdos dos cursos de formação, o questionário continha questões para que o entrevistado discriminasse os conteúdos abordados no curso de formação, se os conteúdos estudados propiciaram segurança para atuar junto ao idoso, e em caso, negativo, quais seriam os conteúdos a acrescentar na matriz curricular (ver tabela 2).

Os conteúdos vão ao encontro das atividades realizadas na rotina diária de trabalho, utilizando a PL 4702/2012 como parâmetro, uma vez que esta discorre acerca das atribuições inerentes à ocupação. Os conteúdos estão muito relacionados a procedimentos, porém há a abordagem de conteúdos relativos à terapia ocupacional e às tecnologias relacionais, uma vez que a habilidade de conversar e ouvir, respeito à individualidade e a religiosidade são abordados nesses cursos.

Houve relatos de que é difícil colocar em prática todo o conhecimento adquirido, mesmo entre aqueles que se consideraram "capacitados" por ter algum tipo de formação profissional. Isto poderia indicar que o interessante nos cursos é o preparo para agir mediante situações do cotidiano e não abordar questões teóricas envolvidas nessas ações ou preparar o egresso para realizar procedimentos de necessidade mais pontual. Assim, pode-se inferir que a formação, apesar de incluir conteúdos relacionados às tecnologias relacionais, essencialmente necessárias ao cuidado, ainda se caracteriza como tecnicista. Os conteúdos referem-se mais ao fazer, mas não contemplam, propriamente, a relação de por que fazer. Importante frisar que todos os entrevistados informaram não saber sobre a carga horária do curso de formação. 
Tabela 2: Conteúdos abordados nos cursos de formação profissional, indicação sobre sua pertinência em viabilizar segurança técnica para o exercício profissional e conteúdos sugeridos que poderiam viabilizar esta segurança, segundo respostas dos cuidadores das ILPIs, Natal, RN, Brasil, 2014.

\begin{tabular}{|c|c|c|c|}
\hline Variável & Categorias & $n$ & $\%$ \\
\hline \multirow{13}{*}{$\begin{array}{c}\text { Conteúdos abordados } \\
\text { no curso de formação } \\
\text { profissional }\end{array}$} & Mudança de decúbito - Prevenção de escaras & 10 & 15,87 \\
\hline & Higiene oral e corporal & 30 & 47,62 \\
\hline & Ajuda na deambulação & 07 & 11,11 \\
\hline & Ajuda na alimentação & 14 & 22,22 \\
\hline & Troca de roupas de cama & 05 & 7,94 \\
\hline & Troca de roupas pessoal & 04 & 6,35 \\
\hline & Troca de fraldas & 04 & 6,35 \\
\hline & Organização do ambiente & 04 & 6,35 \\
\hline & Transferência do leito/cadeira (vice-versa) & 10 & 15,87 \\
\hline & Conversar/saber ouvir & 07 & 11,11 \\
\hline & Respeito à individualidade e à religiosidade & 07 & 11,11 \\
\hline & Carinho/paciência & 11 & 17,46 \\
\hline & Prevenção de quedas e traumas & 04 & 6,35 \\
\hline \multirow{2}{*}{$\begin{array}{c}\text { Segurança para a } \\
\text { prática profissional } \\
(\mathrm{N}=63)\end{array}$} & Sim & 43 & 68,3 \\
\hline & Não & 20 & 31,7 \\
\hline \multirow{5}{*}{$\begin{array}{c}\text { Conteúdos a } \\
\text { acrescentar na matriz } \\
\text { curricular }\end{array}$} & Legislação e ética profissional & 04 & 6,35 \\
\hline & Noções de primeiros socorros & 14 & 22,22 \\
\hline & Saúde do idoso & 12 & 19,05 \\
\hline & Saúde do cuidador & 04 & 6,35 \\
\hline & Lazer e qualidade de vida & 07 & 11,11 \\
\hline
\end{tabular}

Fonte: Pesquisa de campo, Natal, RN, Brasil, 2014.

Um argumento que reforça a necessidade de maior extensão temporal dos cursos, incluindo atividades práticas na matriz curricular e conteúdos curriculares pertinentes a práxis dos cuidadores, é o fato dos entrevistados que realizaram curso específico na área descreverem a importância do trabalho nas ILPIs em sua formação. Por conseguinte, o curso de cuidador em si não lhes forneceu o embasamento prático suficiente, necessitando de uma integração ensinoserviço e, assim, de uma interação teórico-prática. Outro dado captado na pesquisa que reforça a fragilidade da formação é o relato de $88,9 \%$ dos entrevistados $(n=56)$ sobre necessidade em realizar cursos de capacitação, contudo apenas $41,3 \%(n=26)$ disseram haver realizado.

Por conseguinte, pode-se inferir a necessidade de reestruturação do estágio profissional nos cursos de formação do cuidador, assim como inclusão de aulas práticas em cursos de capacitação. Uma sugestão acrescentada por Born (2006) é aproveitar os benefícios do ensino a distância, organizando mais cursos de formação e de educação continuada, desde que haja material didático multimídia e monitores devidamente treinados. Neste sentido, Born (2006) afirma que seria desejável a organização de cursos específicos para os cuidadores formais. Quando não houver condições para cursos específicos, a formação de cuidadores informais e formais poderia ser, inicialmente, num módulo básico com aulas teóricas e teórico-práticas. Na segunda etapa, os cuidadores formais deveriam participar de aulas complementares direcionadas às suas responsabilidades no domicílio do idoso ou na instituição, além de realizar um estágio supervisionado. Enfim, quanto à formação, é necessário, ainda, transpor a formação tecnicista. Administrar medicamentos, dar banho e realizar a alimentação nas horas certas não habilita, necessariamente, o indivíduo para cuidar de idosos. 


\section{CONCLUSÃO}

Este estudo ao buscar analisar a formação profissional dos cuidadores atuantes em Instituições de Longa Permanência para Idosos (ILPIs) em Natal/RN no ano de 2014 através de variáveis socioeconômicas (sexo, estado civil, idade, local de residência, composição familiar, remuneração mensal, renda familiar, escolaridade) e formação profissional (realização de curso específico de cuidador, duração do curso, conteúdos abordados na formação, segurança técnica viabilizada pelos conteúdos abordados, realização de atividades práticas durante o curso, necessidade de curso de capacitação após a formação e realização dessas capacitações), conclui que há necessidade de qualificar a formação do cuidador profissional para que este possa executar com segurança (ausência de lesões devido à assistência à saúde prestada), efetividade (prestação dos serviços baseada no conhecimento científico), eficiência (prevenção do desperdício de suprimentos) e atenção centrada no paciente (respeito às preferências individuais, necessidades e valores do idoso) sua práxis.

Isto porque, embora, a maioria dos entrevistados relate possuir formação específica, predominaram cursos de curta duração, inviabilizando uma articulação teórico-prática no processo ensino-aprendizagem e uma discussão sobre as tecnologias relacionais implicadas no ato de cuidar. Além disso, o nível de escolaridade predominante dos entrevistados, o ensino médio incompleto, dificulta a realização de atividades como a administração de medicamentos. A polifarmácia (uso de diversos medicamentos) é uma realidade comum entre idosos, sendo necessária uma observação atenta do medicamento e da dosagem administrada.

Essas questões relacionadas à fragilidade na formação poderiam ser minimizadas pela regulamentação de uma lei específica para orientar a profissão do cuidador de idosos, posto que o PL 4702/2012 não tem este caráter regulamentador, servindo apenas como um norteador, cuja inobservância não implica em ato ilegal.

Quanto ao perfil dos cuidadores de Natal/RN, observou-se que a profissão tem baixa remuneração (até 01 salário mínimo) e abarca, em sua maioria, mulheres, casadas e com idade entre 40 e 59 anos ( $n=32$ ). Diante das fragilidades da formação, a baixa remuneração da atividade, pode levar os cuidadores a buscarem uma renda adicional. Isto fragilizaria ainda mais a probabilidade de realizarem cursos de capacitação, inferência esta embasada na significativa frequência de indivíduos que relataram necessidade de realizar capacitações e do baixo percentual dos que realizaram. Acredita-se que o cuidador formal de idoso ainda atua por intuição diante de sua identificação pelo ato do cuidar. Neste sentido, a cultura de atribuir ao cuidado uma característica nata ao sexo feminino e a grande representatividade deste sexo na atividade seriam fatores que poderiam subsidiar esta inferência.

Sabe-se que essa "nova" ocupação porta desafios bastante delicados. O relacionamento entre o idoso e o seu cuidador implica numa intervenção terapêutica que pode ser tanto benéfica quanto iatrogênica tendo ressonâncias na vida de ambos. Sendo assim, uma melhoria na educação técnico-científica desses profissionais poderia refletir na diminuição da distância que existe entre o saber e o fazer em nossa realidade assistencial e relacional.

Nesse contexto, sugere-se a realização de mais estudos que insiram na temática do 
envelhecimento populacional os atores presentes no processo - o idoso, o cuidador formal e a família do idoso. Espera-se que este estudo sirva de subsídios para a construção de políticas públicas que visem à melhoria da formação profissional dos cuidadores, o que contribuirá para consequente melhoria da qualidade de vida da população.

\section{REFERÊNCIAS}

1. AGÊNCIA NACIONAL DE VIGILÂNCIA SANITÁRIA (ANVISA). Resolução RDC $\mathbf{n}=\mathbf{2 8 3}$, de $\mathbf{2 6}$ de setembro de 2005. Aprova o regulamento técnico para o funcionamento das instituições de longa permanência para Idosos. Disponível em: <http://portal.anvisa.gov.br/wps/wcm/con nect/58109e00474597429fb1df3fbc4c6735/RDC+N\%C2\%BA+283-2005.pdf?MOD=AJPERES>. Acesso em: 08 ago. 2014.

2. ALONSO, F. R. B. Como envelhece uma população: uma análise demográfica dos componentes do crescimento populacional que conduziram ao acentuado e peculiar processo de envelhecimento da população do munícipio de Santos-SP. In: Encontro Nacional de Estudos Populacionais, 17, Caxambu, 2010. Anais... Belo Horizonte: ABEP, 2010.

3. ARAÚJO, C. A. D. Uma análise sociodemográfica dos cuidadores formais de idosos institucionalizados no município de Natal/RN, 2012. Dissertação (Mestrado em Demografia) - Universidade Federal do Rio Grande do Norte, Natal, 2013.

4. BESSA, M. E. P. et al. Idosas residentes em instituições de longa permanência: uso dos espaços na construção do cotidiano. Acta paul. enferm. v. 25, n. 2, p. 177-182, 2012.

5. BORN, T. A formação de cuidadores: acompanhamento e avaliação. In: Seminário Velhice Fragilizada. Anais... São Paulo: SESC, 2006.

6. BRASIL. República Federativa do Brasil. Câmara dos Deputados. Projeto de Lei no 4702, de 09 de novembro de 2012. Dispõe sobre o exercício da profissão de cuidador de pessoa idosa e dá outras providências. Disponível em: < http://www.camara.gov.br/proposicoesWeb/prop_ mostrarintegra?codteor $=1053572 \&$ filename=Avulso+-PL+4702/2012>. Acesso em: 12 set. 2013.

7. BRASIL. Ministério da Saúde. Portaria Ministerial no 2.528, de 19 de outubro de 2006. Aprova a Política Nacional de Saúde da Pessoa Idosa e dá outras providências. Disponível em:< http://bvsms.saude.gov.br/bvs/saudelegis/gm/2006/prt2528_19_10_2006.html>. Acesso em: 01 de out de 2013.

8. BRASIL. Ministério do Trabalho e Emprego. Classificação brasileira de ocupações. 2002. Disponível em: http://www.mtecbo.gov.br/cbosite/pages/pesquisas/BuscaPorTituloResulta Udo.jsf. Acesso em: 06 ago. 2014.

9. BRASIL. Presidência da República. Casa Civil. Subchefia para Assuntos Jurídicos. Política Nacional de Saúde do Idoso. Regulamentada pela Portaria no 1.395, de dezembro de 1999(a).

10. BRASIL. Ministério da Saúde. Ministério da Previdência e Assistência Social. Portaria Interministerial no 5.153, de 07 de abril de 1999(b). Institui o Programa Nacional de Cuidadores de Idosos a ser coordenado por Comissão Interministerial, constituída por representantes da Secretaria de Estado de Assistência Social do Ministério da Previdência e Assistência e da Secretaria de Políticas de Saúde do Ministério da Saúde. Disponível em: http://www.desenvolvimentosocial.sp.gov.br/a2sitebox/arquivos/documentos/biblioteca/le 
gislacao/portaria5153.pdf. Acesso em: 06 nov. de 2014.

11. CALDAS, C. P. O idoso em processo de demência: o impacto na família. In: MINAYO C. S. M.; COIMBRA JÚNIOR, C. E. A. (Orgs.). Antropologia, saúde e envelhecimento. Rio de Janeiro: Fiocruz. 2002. p. 51-71.

12. CAMARANO, A. A.; KANSO S. As instituições de longa permanência para idosos no Brasil. Rev. Bras. Estud. Popul., v. 27, n. 1, p. 233-235, 2010.

13. CAMARANO, A. A.; PASINATO, M. T. O envelhecimento populacional na agenda das políticas públicas. In: CAMARANO, A. A. (Org.). Os novos idosos brasileiros. Rio de Janeiro: IPEA, 2004. p. 253-292.

14. FREITAS, A. V. S.; NORONHA, C. V. Idosos em instituições de longa permanência: falando de cuidado. Interface - Comunicação, Saúde, Educação, v. 14, n. 33, p. 359-369, 2010.

15. GAIOLI, C. C. L. O.; FUREGATO, A. R. F.; SANTOS, J. L. F. Perfil de cuidadores de idosos com doença de Alzheimer associado à resiliência. Texto Contexto Enfermagem, v. 21, n. 1, p. 150157, 2012.

16. INOUYE, K; PEDRAZZANI, E. S.; PAVARINI, S. C. I. Implicações da doença de Alzheimer na qualidade de vida do cuidador: um estudo comparativo. Caderno Saúde Pública, v. 26, n. 5, p. 891-899, 2010.

17. INSTITUTO BRASILEIRO DE GEOGRAFIA E ESTATÍ́STICA (IBGE). Síntese de Indicadores Sociais: uma análise das condições de vida da população brasileira. Rio de Janeiro: IBGE, 2010.

18. KARSCH, Ú. M. Idosos dependentes: famílias e cuidadores. Cad. Saúde Pública, v. 19, n. 3, p. 861-866, 2003.

19. LIMA, C. R. V. Políticas públicas para idosos: a realidade das instituições de longa permanência no Distrito Federal. Monografia (Especialização em Legislativo e Políticas Públicas) - Programa de Pós-graduação do Centro de Formação, Treinamento e Aperfeiçoamento - CEFOR, Câmara dos Deputados, Brasília, 2011.

20. MENDES, E. V. As redes de atenção à saúde. Ciênc. Saúde Coletiva, v. 15, n. 5, p. 2297-2305, 2010.

21. NATAL. Prefeitura Municipal de Natal. Decreto № 8.553 de 02 de outubro de 2008. Aprova a Norma Técnica Especial que regulamenta o funcionamento de Instituições de Longa Permanência destinadas a idosos no município de Natal. Disponível em: http://www.normasbrasil.com.br/norma/decreto-8553-2008-natal_175683.html. Acesso em: 01 jul. 2014.

22. PERPÉTUO, I. H. O.; WONG, L. R. Programas y políticas nacionales que afectaron el curso de la fecundidad en el Brasil. Seminar La Fecundidad en América Latina y El Caribe: Transición o Revolución? Santiago, Chile: Celade, 2003. (Serie Seminarios y Conferencias).

23. RIBEIRO, M. T. et al. Perfil dos cuidadores de idosos nas instituições de longa permanência de Belo Horizonte, MG. Ciênc. Saúde Coletiva., v. 13, n. 4, p. 1285-1292, 2008.

24. ROCHA, M. P. F. et al. Desvelando o cotidiano dos cuidadores informais de idosos. Rev. Bras. Enferm., v. 61, n. 6, p. 801-808, 2008.

25. SALIBA, N. A. et al. Perfil de cuidadores de idosos e percepção sobre saúde bucal. Rev. Interface: Comum., Saúde, Educ., v. 11, n. 21, p. 39-50, 2007. 
26. SILVA, M. C. O processo de envelhecimento no Brasil: desafios e perspectivas. Textos Envelhecimento. v. 8. n. 1, p. 43-60, 2005.

27. SIMSON, O. R. M. V.; PINTO, S. P. L. C. Instituições de longa permanência para idosos no Brasil: sumário da legislação. Rev. Bras. Geriatr. Geront., v. 15, n. 1, p. 169-174, 2012.

28. WONG, L. L. R; CARVALHO, J. A. O rápido processo de envelhecimento populacional no Brasil: sérios desafios para as políticas públicas. Rev. Bras. Estat.1 Popul., v. 23, n.1, p. 5-26, 2006. 